\title{
Abnormal radiofurosemide binding by Tamm Horsfall glycoprotein of diabetic patients
}

\author{
J. Dulawa, M. Rambausek, K. Jann, M. Notohamiprodjo and E. Ritz \\ Department of Internal Medicine, University of Heidelberg and Max-Planck-Institut für Immunologie Freiburg, FRG
}

\begin{abstract}
Summary. In the present study, 8 Type 1 diabetic patients with normal creatinine clearance and 8 matched controls were examined. Tamm Horsfall glycoprotein was isolated with the $\mathrm{NaCl}$ precipitation procedure. Its purity was checked by gelelectrophoresis, immunodiffusion and isoelectric focussing. Tamm Horsfall glycoprotein of diabetic patients had higher glucose $(p<0.05)$ and lower $\mathrm{N}$-acetylneuraminic acid content $(p<0.01)$ than controls. ${ }^{14} \mathrm{C}$-furosemide binding by Tamm Horsfall glycoprotein was examined using an Amicon ultrafiltration system at $0^{\circ} \mathrm{C}$. In nominally sodium-free medium, furosemide binding by Tamm Horsfall glycoprotein was significantly $(p<0.01)$ higher in diabetic patients than in matched controls. The increment of binding capacity with sodium was
\end{abstract}

similar in controls and diabetic patients so that maximal binding capacity in a $\mathrm{NaCl}$ system was $1.7 \pm 0.3$ in controls and $3.64 \pm 0.5$ in diabetic patients $(p<0.025)$. Half maximal furosemide binding by Tamm Horsfall glycoprotein occured at $1.4 \pm 0.2 \mathrm{mmol} \mathrm{Na} / 1$ in controls and $0.52 \pm 0.12$ in diabetic patients $(p<0.01)$. Abnormal radiofurosemide binding of Tamm Horsfall glycoprotein of diabetic patients may be the consequence of abnormal postribosomal modification of the glycoprotein which is synthesized in an insulin- and glucosesensitive nephron segment.

Key words: Diabetes mellitus, renal sodium transport, Tamm Horsfall glycoprotein, furosemide.
Tamm Horsfall glycoprotein (THP) is a glycoprotein originally described by Tamm and Horsfall in 1950 [1]. Its participation in some pathological conditions of kidney and urinary tract has recently been discussed [2]. However, its physiological rôle remains unknown.

It is known that THP is present on all plasma membranes of cells in the thick ascending loop of Henle [2]. The topography of its location and phylogenetic and ontogenetic studies suggest a relation to specific functions of the diluting segment $[2,3]$. It has recently been demonstrated that THP binds furosemide $\mathrm{Na}^{+}, \mathrm{K}^{+}$, and $\mathrm{Cl}^{-}$-dependently in a saturable fashion [4]. The sodium concentration needed for half maximal binding was $1.4-3.3 \mathrm{mmol} / 1$ [4], a figure remarkably similar to the sodium concentration found to half maximally stimulate active transport of sodium in the isolated perfused thick ascending loop of Henle [5]. Furthermore, the concentration of furosemide required for half maximal binding to THP is similar to the concentration that half maximally inhibits $\mathrm{Na}^{+}, \mathrm{K}^{+}, 2 \mathrm{Cl}^{-}$cotransport of the thick ascending loop of Henle in vitro [6]. Renal sodium handling is abnormal in clinical or experimental states of insulin deficiency or excess [7-9]. Furthermore, we have previously demonstrated abnormal carbohydrate composition of THP in non-proteinuric patients with Type 1 diabetes [10]. These considerations prompted us to investigate whether furosemide binding by THP is abnormal in diabetes mellitus.

\section{Subjects and methods}

\section{Subjects}

We examined 8 Type 1 diabetic patients, 5 male, 3 female, with a known median duration of diabetes of 17.6 years (range 1-33). Metabolic control varied widely as indicated by $\mathrm{HbA}_{1}$ values (fast haemoglobin test system, Panchem, Kleinwallstadt, FRG, normal range $5-7.5 \%$ ). Because albuminuria and bacteriuria may interfere with isolation of THP, patients were selected without albuminuria on first presentation, as tested with a stix (Combur; detection threshold $\supseteq$ $30 \mathrm{mg} / \mathrm{dl}$ ) and without significant bacteriuria (dip slide technique, Uricult). Urinary protein was then measured in 24-h urine collections with Biuret, and endogenous creatinine clearance with standard autoanalyzer technique. None of the patients had secondary complications, e.g. impaired renal function (serum creatinine $\geq 115 \mu \mathrm{mol} / \mathrm{l}$ ), hypertension (blood pressure $>140 / 90 \mathrm{mmHg}$ ) and proliferative retinopathy. Pertinent clinical data are given in Table 1.

Members of the staff of the renal clinic ( 6 male, 2 female) served as age- and sex-matched controls. None of the patients or probands had medication other than insulin.

The study was carried out on an outpatient basis with patients and probands on their usual diets. Twenty-four hour urine was collected in two 1 polyvinylchloride bottles to which $30 \mathrm{mg} \mathrm{Na}$-azide had been added. Pilot studies had shown that $>90 \%$ of THP added to urine was recovered from the bottles (excluding adsorption to the PVC wall or interference of azide with THP recovery).

\section{Isolation of Tamm Horsfall glycoprotein and tests for purity of preparation}

THP was isolated by repeated precipitation with $0.58 \mathrm{M} \mathrm{NaCl}$ according to the original method of Tamm and Horsfall [1]. The THP precip- 
Table 1. Clinical data

\begin{tabular}{|c|c|c|c|c|c|c|c|c|c|c|c|c|}
\hline \multicolumn{7}{|c|}{ Diabetic patients } & \multicolumn{6}{|c|}{ Control subjects } \\
\hline R.B. f & 53 & 33 & 85 & $140 / 80$ & 500 & 7.1 & R.E. m & 48 & 115 & $140 / 80$ & 130 & 7.1 \\
\hline H.K. m & 49 & 19 & 94 & $140 / 80$ & 70 & 7.1 & D.J. $\mathrm{m}$ & 28 & 120 & $130 / 70$ & 138 & 5.5 \\
\hline St. M. m & 46 & 17 & 140 & $130 / 80$ & 67 & 8.1 & R.M. m & 31 & 125 & $140 / 80$ & 145 & 7.2 \\
\hline P.V. m & 46 & 18 & 134 & $140 / 80$ & 700 & 11.2 & N.M. m & 31 & 108 & $110 / 80$ & 180 & 6.1 \\
\hline K.C. $m$ & 41 & 16 & 140 & $110 / 80$ & 800 & 13.2 & E.M. $\mathrm{f}$ & 42 & 117 & $140 / 85$ & 197 & 7.3 \\
\hline R.F. $f$ & 28 & 1 & 125 & $105 / 75$ & 67 & 17.1 & N.F. $m$ & 39 & 106 & $110 / 70$ & 78 & 6.5 \\
\hline
\end{tabular}

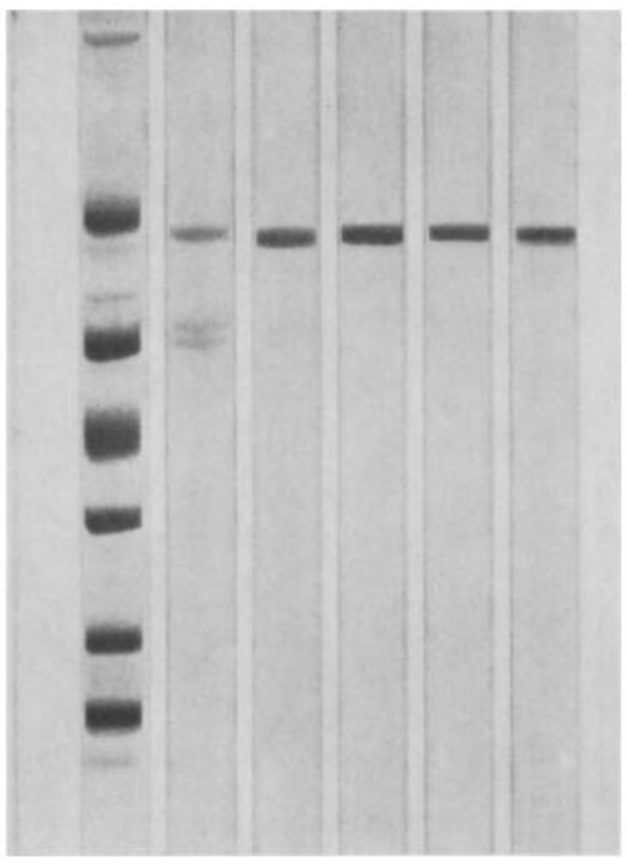

Fig. 1. SDS PAGE of Tamm Horsfall protein of diabetic and control subjects Lane 1 reference proteins (fibrinogen $300 \mathrm{kD}$, transferrin $83 \mathrm{kD}$, BSA $68 \mathrm{kD}$, catalase $60 \mathrm{kD}$, ovalbumin $45 \mathrm{kD}$, aldolase $40 \mathrm{kD}$, trypsin $23.5 \mathrm{kD}$ ). Lane 2 control THP with contamination of albumin, sample discarded; Lane 3-4 control THP, Lane 5-6 diabetic THP

itate was dialysed (Visking dialysis tubing, type 36/32, Serva Co., Heidelberg, FRG) against distilled water and concentrated by Amicon ultrafiltration (Amicon Co., Ditten/Ruhr, FRG; filter XM 50, transmembrane pressure 5 bar). All steps were carried out at $4{ }^{\circ} \mathrm{C}$. The final THP preparation was freeze dried.

To evaluate the puritiy of the THP preparation used, all samples were subjected to polyacrylamide gelelectrophoresis in sodium-dodecylsulfate (SDS PAGE), Ouchterlony immunodiffusion and isoelectric focusing. Proteins other than THP were not demonstrable in any of the preparations used for the binding studies.

SDS PAGE was carried out according to Laemmli [11]. Ten percent polyacrylamide slab gels ( $2 \mathrm{~mm}$ thick, $12 \mathrm{~mm}$ high) were used with $2.5 \%$ stacking gel $(2.5 \mathrm{~cm}$ high). After electrophoresis, the gels were stained for $1 \mathrm{~h}$ in a solution of $0.02 \%$ Coomassie brilliant blue in a mixture of $25 \%$ methanol and $10 \%$ acetic acid in water. They were subsequently destained overnight in the same solution without Coomassie-blue. Reference proteins of known molecular weight were added to a parallel gel as reference proteins (Fig. 1). THP migrated as one single band, staining with Coomassie-blue and PAS, but not with $0.2 \%$ Toluidine blue and had an estimated molecular weight of $80 \mathrm{kD}$.

In parallel, samples were examined by double immunodiffusion according to Ouchterlony. Plates were prepared with $1 \%$ immunodiffusion agar in barbiturate buffer ( $\mathrm{pH} 8.6)$ according to LKB application note 294. Ten $\mathrm{mg}$ samples of freeze dried THP were dissolved in $1 \mathrm{ml}$ of Tris-glycine buffer $(1.5 \mathrm{M} ; \mathrm{pH} 8.8)$ and tested against antihuman uromucoid serum (Behring Company, Marburg, FRG, catalogue number $1726 \mathrm{~L}$ ) and, in addition, against antiserum to human albumin (Behring Company, catalogue number A 10118 B) and to human serum (Behring Company, catalogue number $100109 \mathrm{H}$ ). THP yielded one precipitation band with human uromucoid antiserum and did not precipitate with antiserum to human serum or antiserum to human albumin.

Isoelectric focusing (IEF) was carried out in LKB 2117 Multiphor apparatus at $10^{\circ} \mathrm{C}$ and $6 \mathrm{~W}$ with a maximum voltage of $1200 \mathrm{~V}$ for $3 \mathrm{~h}$. The preparations failed to migrate in the absence of $6 \mathrm{M}$ urea. Samples were prepared with Servalyte $\mathrm{pH}$ 2-11 (Serva Company, Heidelberg, FRG). The suspension was degassed, poured into a $23 \times 11 \mathrm{~cm}$ tray and dried according to Radola [12]. IEF showed presence of one poorly resolved band with a pI of approximately 4 and no contaminating bands between $\mathrm{pH} 2.5$ to 10.0 .

\section{Chemical analysis of Tamm Horsfall glycoprotein}

THP protein concentration was determined according to Lowry [13]. Neutral sugars were determined as their alditol acetate [14] by gasliquid chromatography. Analyses of amino-sugars were carried out using an aminoacid analyser (LKB 440). N-acetyl-neuraminic acid (NANA) was determined colorimetrically using the thiobarbiturate method of Warren [15].

\section{${ }^{14}$ C-furosemide binding}

The method described by Greven et al. [4] was used. In brief, $8 \times 10^{-5} \mathrm{M} / 1{ }^{14} \mathrm{C}$-furosemide (specific activity $25 \mathrm{Ci} / \mathrm{mmol}$, kindly supplied by Hoechst Company, Frankfurt/Main, FRG) was incubated for $30 \mathrm{~min}$ at $0^{\circ} \mathrm{C}$ in a medium consisting of $2.5 \mathrm{mg} / \mathrm{ml} \mathrm{THP}$, $4 \mathrm{mmol} / 1$ Tris-buffer $(\mathrm{pH} 8)$ and ions. Bound and free ${ }^{14} \mathrm{C}$-furosemide were separated by 5 min centrifugation through an Amicon filter (YM $5 \varnothing 14 \mathrm{~mm}$ ). All measurements were carried out at least in duplicate. ${ }^{14} \mathrm{C}$ activity in the filtrate was determined using scintillation counting techniques. Reproducibility of measurements in replicate determinations was typically better $\pm 7 \%$.

\section{Statistics}

Data are given $\bar{x} \pm$ SEM. Differences between groups were analyzed using both non-parametric Wilcoxon test and analysis of variance. Correlations were examined using linear regression analysis. 


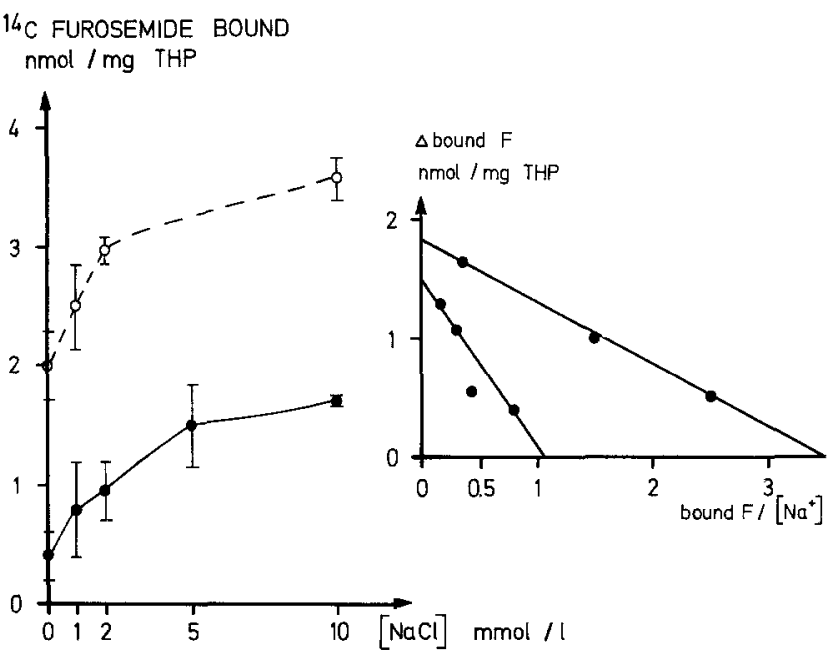

Fig. 2. Sodium-dependent ${ }^{14} \mathrm{C}$-furosemide binding of THP of diabetic patients and control subjects. Data as $\bar{x} \pm$ SEM. 8 individuals per group. Values for each individual measured at least in duplicate. Significant $(p<0.01)$ difference between diabetic patients and controls (analysis of variance). The insert shows the activating sodium concentration required for half maximal binding; $y=$ furosemide bound (nmol/mg THP) at given $\left[\mathrm{Na}^{+}\right]$minus furosemide bound in nominally sodium-free medium; $x=$ bound furosemide (nmol/mg THP): $\mathrm{Na}^{+}$ (mmol/l), $\mathrm{O}----\mathrm{O}$ diabetic patients;

${ }^{14} \mathrm{C}$ FUROSEMIDE BOUND

$\mathrm{nmol} / \mathrm{mg}$ THP

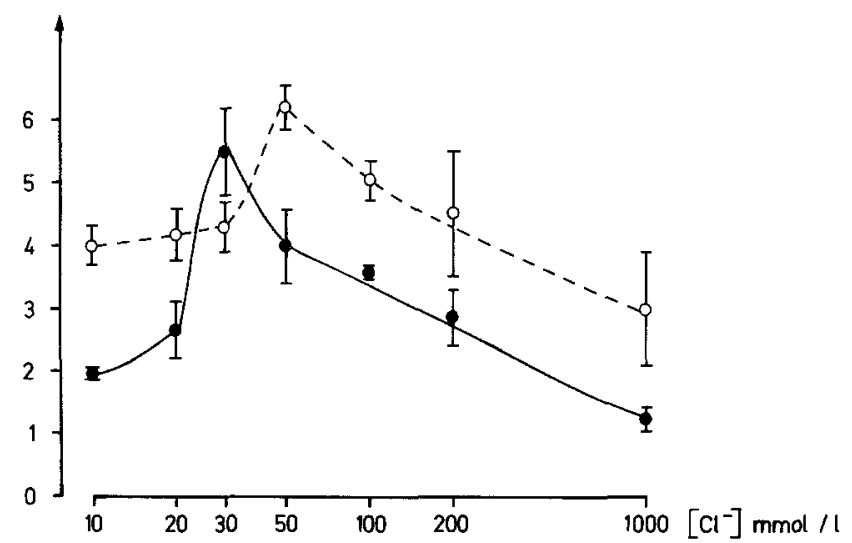

Fig. 3. Displacement of bound ${ }^{14} \mathrm{C}$-furosemide from Tamm Horsfall glycoprotein by $\mathrm{Cl}^{-}$. Data as $\bar{x} \pm$ SEM. $n=8$ per group. Values for each individual measured at least in duplicate. $\mathrm{Na}^{+}$concentration was kept constant at $10 \mathrm{mmol} / 1$ and $\mathrm{Cl}^{-}$concentration was adjusted by addition of choline chloride. O-.--O Diabetic patients; $\longrightarrow$ control subjects

Table 2. Chemical composition of Tamm Horsfall glycoprotein of diabetic patients

\begin{tabular}{lcll}
\hline (mg/100 mg THP) & $\begin{array}{l}\text { Control } \\
\text { Subjects } \\
(n=38)\end{array}$ & $\begin{array}{l}\text { Diabetic } \\
\text { Patients } \\
(n=8)\end{array}$ & Difference \\
\hline Protein & $77.3 \pm 1.5$ & $77.7 \pm 1.9$ & NS \\
Galactose & $4.51 \pm 0.38$ & $4.33 \pm 0.21$ & NS \\
Glucose & $0.65 \pm 0.21$ & $1.71 \pm 0.21$ & 0.01 \\
N-acetyl-neuraminic & $5.10 \pm 0.19$ & $3.28 \pm 0.24$ & 0.001 \\
acid & & & \\
\hline
\end{tabular}

Results

\section{Chemical analysis of Tamm Horsfall glycoprotein}

As shown in Table 2, protein content of THP was similar in diabetic patients and control subjects. In contrast, glucose content was slightly increased while $\mathrm{N}$-acetylneuraminic acid content was markedly decreased.

\section{$\mathrm{Na}^{+}$-dependent binding of ${ }^{14} \mathrm{C}$-furosemide to Tamm Horsfall glycoprotein}

Fig. 2 shows binding of ${ }^{14} \mathrm{C}$-furosemide $\left(8 \times 10^{-5} \mathrm{M} / \mathrm{l}\right)$ to THP with increasing concentrations of $\mathrm{NaCl}$ in the incubation medium. In nominally $\mathrm{NaCl}$-free medium, binding of ${ }^{14} \mathrm{C}$-furosemide to THP was $0.4 \pm 0.2 \mathrm{nmol} /$ $\mathrm{mg}$ THP in controls and $2.0 \pm 0.3$ in diabetic patients $(p<0.01)$. Binding increased with increasing $\mathrm{NaCl}$ concentrations and reached saturation at $\mathrm{NaCl}$ concentrations above $5 \mathrm{mmol} / 1$. The amount of ${ }^{14} \mathrm{C}$ furosemide bound was significantly higher in diabetic patients at any given ambient $\mathrm{Na}^{+}$concentration. However, the increment of binding capacity above basal binding in nominally $\mathrm{Na}^{+}$free medium was similar for controls and diabetic patients $(\Delta 1.3 \pm 0.2 \mathrm{nmol} / \mathrm{mg} \mathrm{THP}$, and $1.64 \pm 0.32$ in controls and diabetic patients, respectively).

Linear transformation of the binding isotherm (insert to Fig.2) revealed that half maximal binding was reached at a $\mathrm{Na}^{+}$concentration of $1.4 \mathrm{mmol} / 1$ for THP in control subjects, and $0.52 \mathrm{mmol} / 1$ for THP in diabetic patients.

No significant correlation between ${ }^{14} \mathrm{C}$ furosemide binding and serum $\mathrm{HbA}_{1}$, urinary glucose or duration of diabetes was found.

\section{Displacement of bound ${ }^{14} \mathrm{C}$-furosemide from Tamm Horsfall glycoprotein by $\mathrm{Cl}^{-}$}

As shown in Fig. 3, the amount of ${ }^{14} \mathrm{C}$-furosemide bound was a function of ambient $\mathrm{Cl}^{-}$concentration for both THP in controls and THP in diabetic patients. In the experiment depicted, $\mathrm{Cl}^{-}$concentration was varied through addition of choline chlorideat constant $\mathrm{Na}^{+}$ concentration $(10 \mathrm{mmol} / 1)$. THP in control subjects showed significantly $(p<0.01)$ lower binding at $10 \mathrm{mmol} / 1 \mathrm{Cl}^{-}$than THP in diabetic patients. The binding maximum occured at lower ambient $\mathrm{Cl}^{-}$concentration ( $\left.30 \mathrm{vs} 50 \mathrm{mmol} / 1 \mathrm{CL}^{-}\right)$. At higher $\mathrm{Cl}^{-}$concentrations, binding was lower for THP in control subjects at any given $\mathrm{Cl}^{-}$concentration than for THP in diabetic patients.

\section{Discussion}

The present study clearly demonstrates that THP of patients with Type 1 diabetes exhibits altered radiofurose- 
mide binding characteristics when compared with THP of age-matched controls.

Kinetic analyses revealed higher basal sodium independent binding capacity for THP of diabetic patients in nominally $\mathrm{Na}^{+}$-free medium, but a similar increment of binding capacity with sodium resulting in increased maximal binding capacity at saturating concentrations of $\mathrm{Na}^{+}$.

Such abnormal ${ }^{14} \mathrm{C}$-furosemide binding cannot be explained as an artefact of THP protein content, since diabetic and control THP contained similar amounts of protein as evaluated by the Lowry technique. The cause of abnormal binding may be related to altered composition of the carbohydrate moiety of THP. Chemical analyses showed that THP of diabetic patients had increased glucose, unchanged galactose and diminished $\mathrm{N}$-acetyl-neuraminic acid content. Such compositional abnormalities of THP are of interest in view of the recent demonstration of Lloyd et al. [16] of increased nondialysable conjugates of glucose with unchanged galactose content in urines of diabetic patients. This may be a reflection of the above change of composition of THP, perhaps in parallel with other urinary glycoproteins, in diabetes mellitus.

The functional consequences of altered THP carbohydrate composition are unknown. In contrast to the almost invariant amino acid composition of THP from different species, the THP carbohydrate component is remarkably variable $[2,17,18]$. It is unknown whether changes of carbohydrate composition have major functional consequences. The Tamm Horsfall glycoprotein is an exclusive product of tubular cells in the thick ascending loop of Henle $[2,3]$. These cells are known to phenotypically express insulin receptors [19] and to depend on uptake and aerobic metabolism of glucose [20]. In the genesis of abnormal carbohydrate composition of THP of diabetic patients, a role must be discussed for either insulin deficiency or abnormal pericellular glucose concentration (hyperglycemia and/or increased tubular delivery of glucose) or both.

Acknowledgements. Dr. Dulawa (present address: Department Nephrology, Katowice/Poland) received a scholarship from Gambro Company (München, FRG). The work was supported by Deutsche Forschungsgemeinschaft ( $\mathrm{Ra} 367 / 1-1)$. We thank Ms. J. Koderisch for help in analytical techniques, Professor Dr. Greven (Pharmakologisches Institut, Rheinisch Westfälische Technische Hochschule Aachen, FRG) for helpful suggestions. Ms. D. Scheel (Max-PlanckInstitut für Immunologie, Freiburg, FRG) for help in isoelectric focussing and Ms. U. Stelz for typing the manuscript.

\section{References}

1. Tamm I, Horsfall FL (1950) Characterization and separation of an inhibitor of viral hemaglutination present in urine. Proc Soc Exp Biol Med 74: 108-114

2. Hoyer JR, Seiler MW (1979) Pathophysiology of Tamm Horsfall protein. Kidney Int 16:279-289
3. Richet G (1983) The mechanisms of action of some loop-acting diuretics. Role of binding to Tamm Horsfall protein. Clin Nephrol 19: S 42-S 44

4. Greven J, Kölling B, Bronevski-Schwarzer B, Junker M, Neffgen B, Nilius RM (1983) Evidence for a role of the Tamm Horsfall protein in the tubular action of furosemide-like loop diuretics. In: Puschett JP, Greenberg A (eds) Diuretics, chemistry, pharmacology and clinical application. Elsevier, New York Amsterdam Oxford, pp 203-214

5. Greger R (1981) Chloride reabsorption in the rabbit cortical thick ascending limb of the loop of Henle. A sodium-dependent process. Pflüg Arch 390: 38-43

6. Schlatter E, Greger R, Weidtke C (1983) Effect of "high ceiling" diuretics on active salt transport in the cortical thick ascending limb of Henle's loop of rabbit kidney. Pflüg Arch 369: 210-217

7. Chatel R de, Weidmann P, Flammer J, Ziegler WM, Beretta-Piccoli E, Vetter W, Reubi FC (1977) Sodium, renin, aldosterone, catecholamines and blood pressure in diabetes mellitus. Kidney Int 12: 412-421

8. Carney SL, Wong NLM, Dirks $J \mathbf{H}$ (1979) Acute effects of streptozotocin diabetes on rat renal function. J Lab Clin Med 93: 950-961

9. Saudek CD, Boulter PR, Knopp RH, Arky RA (1974) Sodium retention accompanying insulin treatment of diabeties meilitus. Diabetes $23: 240-246$

10. Rambausek M, Rahm HJ, Jann K, Notohamiprodjo M, Ritz E (1984) Abnormal glycosylation of Tamm Horsfall protein in diabetes (Abstract). Kidney Int 25:237a

11. Laemmli UK (1970) Cleavage of structural proteins during the assembly of the head of bacteriophage $T_{4}$. Nature 227: 680-685

12. Radola BJ (1974) Isoelectric focussing in layers of granulated gels. II.Preparative isoelectric focussing. Biochim Biophys Acta 386: $181-195$

13. Lowry OH, Rosebrough NJ, Farr AL, Randall RJ (1951) Protein measurement with the Folin phenol reagent. J Biol Chem 193: $265-275$

14. Savardeker JS, Sloneker IH, Jeanes AR (1965) Quantitative determination of monosaccharides as their alditol acetates by gas liquid chromatography. Anal Chem 12: 1602-1610

15. Warren L (1959) The thiobarbituric acid assay of sialic acid. J Biol Chem 234: 191-200.

16. Lloyd P. Hockaday TDR, Randle PJ (1984) Urinary excretion of nondialysable conjugates of glucose and galactose in normal people and diabetic patients. Diabetologia 27: 433-436

17. Marr AMS, Neuberger A, Ratcliffe WA (1971) Rabbit Tamm Horsfall urinary glycoprotein: Chemical composition and subunit structure. Biochem J 122: 623-631

18. Neuberger A, Ratcliffe WA (1972) The acid and enzymatic hydrolysis of O-acetylated sialic acid residues from rabbit Tamm Horsfall protein. Biochem J 129: 683 -693

19. Nakamura R, Emmanouel D, Katz IA (1983) Insulin binding sites in various segments of the rabbit nephron. $J$ Clin Invest 72 : 388-392

20. Wittner M, Schlatter E, Weidtke C, Greger R (1983) Aerobic glucose metabolism, the main energy source for active $\mathrm{NaCl}$ transport in the cortical thick ascending limb of Henle's loop in rabbit nephron (abstr.). Eur J Clin Invest 13: 6, 32

Received: 11 February 1985

and in revised form: 12 September 1985

Professor Dr. E. Ritz

Department Internal Medicine

University of Heidelberg

Bergheimer Straße 56a

D-6900 Heidelberg

FRG 